Francineide Silva Sales

\title{
Adolescente-etiqueta: consumo, significados e conflitos
}

Dissertação de Mestrado

Dissertação apresentada como requisito parcial para obtenção do grau de Mestre pelo Programa de Pósgraduação em Serviço Social do Departamento de Serviço Social da PUC-Rio.

Orientadora: Prof. Marilena Jamur

Rio de Janeiro

Abril de 2005 


\section{Francineide Silva Sales}

\section{Adolescente-etiqueta: consumo, significados e conflitos.}

Dissertação apresentada como requisito parcial para obtenção do grau de Mestre pelo Programa de Pósgraduação em Serviço Social do Departamento de Serviço Social da PUC-Rio. Aprovada pela Comissão Examinadora abaixo assinada.

Prof. Marilena Jamur

Orientadora

Departamento de Serviço Social - PUC-Rio

Prof. Angela Arruda Instituto de Psicologia - UFRJ

Prof. Rosemere dos Santos Maia Escola de Serviço Social - UFRJ

Prof. João Pontes Nogueira Vice-decano de Pós-graduação Do Centro de Ciências Sociais - PUC-Rio

Rio de Janeiro, 25 de abril de 2005. 
Todos os direitos reservados. É proibida a reprodução total ou parcial do trabalho sem autorização da universidade, da autora e do orientador.

\section{Francineide Silva Sales}

Graduou-se em Serviço Social na Faculdade de Serviço Social da Universidade do Estado do Rio de Janeiro UERJ - em 1998.

Ficha catalográfica

Sales, Francineide Silva

Adolescente-etiqueta : consumo, significados e conflitos / Francineide Silva Sales ; orientadora: Marilena Jamur. - Rio de Janeiro : PUC-Rio, Departamento de Serviço Social, 2005.

96 f. ; $30 \mathrm{~cm}$

Dissertação (mestrado) - Pontifícia Universidade Católica do Rio de Janeiro, Departamento de Serviço Social.

Inclui referências bibliográficas

1. Serviço Social - Teses. 2. Adolescente. 3. Consumo. 4. Identidade. 5. Representações sociais. I. Jamur, Marilena. II. Pontifícia Universidade Católica do Rio de Janeiro. Departamento de Serviço Social. III. Título.

CDD: 361 
Para Maria da Luz, pelo amor e apoio, e ao Deus da minha vida por tê-la escolhido para ser minha mãe. 


\section{Agradecimentos}

À minha orientadora Professora Marilena Jamur pelo estímulo, paciência e calma transmitidos em todos os momentos, inclusive os de crise.

Ao CNPq e à PUC-Rio, pelos auxílios concedidos, sem os quais este trabalho não poderia ter sido realizado.

Às professoras Rosemere dos Santos Maia e Ângela Arruda, que fizeram parte da Comissão Examinadora, e à professora Ana Quiroga pelas inestimáveis contribuições e generosidade.

Às professoras Zélia Seiblitz e Sueli Bulhões pelo apoio.

Aos amigos e colegas de mestrado, em especial a Débora Souza e Jussara Ferreira, pelas constantes trocas e solidariedade nos momentos difíceis.

À professora Sueli Jorge, Secretária de Ensino do Colégio Pedro II, e demais funcionários pelas portas abertas que, depois de muitos anos, fizeram com que eu me sentisse outra vez em casa.

Ao Departamento Geral de Ensino da Secretaria Municipal de Educação do Rio de Janeiro e à $2^{\mathrm{a}}$ Coordenadoria Regional de Educação.

À minha família, o ninho de todas as horas. 


\section{Resumo}

Sales, Francineide Silva; Jamur, Marilena. Adolescente-etiqueta: consumo, significados e conflitos. Rio de Janeiro, 2005. 96p. Dissertação de Mestrado Departamento de Serviço Social, Pontifícia Universidade Católica do Rio de Janeiro.

A dissertação aqui apresentada trata das representações sociais e dos significados construídos por adolescentes cariocas em sua relação com o consumo. Durante a pesquisa, alguns elementos concernentes a essa relação foram abordados no processo de observação a respeito dos valores conferidos à moda e à marca na construção da imagem dos adolescentes. A discussão em torno do papel da indústria cultural e de suas estratégias nesse processo, os limites das táticas adolescentes, bem como da própria definição de sua identidade integram o trabalho. Um passaporte para o mundo adulto ou meio de distinção em relação ao mesmo; uma tática de produção de uma imagem assimilável pela sociedade; uma tática de pertencimento a um grupo social; ou um meio de acesso a elementos que trazem bem-estar, foram alguns dos significados atribuídos ao consumo observados durante a pesquisa.

\section{Palavras-chave}

Adolescente; consumo; identidade; representações sociais. 


\section{Résumé}

Sales, Francineide Silva; Jamur, Marilena. Adolescent-étiquette: consommation, signifiés et conflits. Rio de Janeiro, 2005. 96p. Dissertação de Mestrado Departamento de Serviço Social, Pontifícia Universidade Católica do Rio de Janeiro.

L'étude ici présentée porte sur les représentations sociales et les significations construites par des adolescentes cariocas dans leurs rapports à la consommation. Quelques éléments concernant ces rapports ont été traités dans le processus de recherche, sous l'angle des valeurs attribuées à la mode et à la marque, dans la construction de l'image des adolescents. La discussion autour du rôle de la industrie culturelle et de ses stratégies dans ce processus, les limites des tactiques des adolescents, aussi que la définition même de leur identité, intégrent ce travail. Tout le long de la recherche, quelques signifiés attribués par les adolescents ont été repérés: un passeport vers le monde des adultes, ou un moyen de se distinguer para rapport à celui-ci; une tactique pour produire une image assimilable par la société; une tactique d'appartenance à un groupe social; ou bien une forme qui donne accès à des éléments qui apportent bien-être.

\section{Mots-clés:}

Adolescents; consommation; identité; représentations sociales 
SUMÁRIO

Lista de tabelas e gráficos 9

1. Introdução 10

2. Adolescente sob o olhar da indústria cultural 13

2.1 Uma narrativa televisiva sobre o consumo adolescente 13

2.2 O episódio 14

2.3 Um mergulho no tema $\quad 16$

2.4 Uólace e João Victor: personagens da vida real? 28

3. Sobre adolescentes e adolescentes 32

3.1 Do menor ao adolescente 34

3.2 Identidade juvenil 39

1. Adolescente-etiqueta? 49

4.1 Caminhos percorridos $\quad 49$

4.2 Mundo adolescente versus mundo adulto $\quad 59$

4.3 Em busca da felicidade $\quad 69$

$\begin{array}{ll}\text { 4.4 Mimetismo e pertencimento } & 77\end{array}$

2. Conclusões 87

3. Referências bibliográficas 92

$\begin{array}{ll}\text { Anexos } & 95\end{array}$ 


\section{Lista de tabelas e gráficos}

Tabela $1 \quad 29$

Tabela $2 \quad 29$

Tabela $3 \quad 30$

Tabela 4

$\begin{array}{ll}\text { Tabela } 5 & 38\end{array}$

Gráfico 1 - Consumo como meio de acesso ao mundo adulto, segundo as respostas dos alunos dos dois estabelecimentos de ensino.

Gráfico 2 - Consumo como meio de acesso ao mundo adulto, segundo as respostas dos alunos da EMPJG.

Gráfico 3 - Consumo como meio de acesso ao mundo adulto, segundo as respostas dos alunos do CPII.

Gráfico 4 - Itens preferidos pelos alunos da EMPJG. 69

Gráfico 5 - Itens preferidos pelos alunos do CPII. $\quad 70$

Gráfico 6 - Relação com as roupas entre os alunos da EMPJG. $\quad 74$

Gráfico 7 - Relação com as roupas entre os alunos do CPII.

Gráfico 8 - Moda e seus significados entre alunos da EMPJG. 82

Gráfico 9 - Moda e seus significados entre alunos do CPII. 83 